\title{
Cuidados Paliativos Numa Visão Humanizada da Assistência de Enfermagem: Revisão Integrativa
}

\author{
Silva, Raymara Alves da; Silva, Liniker Scolfild R. da; Fonsêca, Jéssica Ramalho da; \\ Ramos, Ana Raquel Xavier; Correia, Nathália da Silva; Cordeiro, Eliana Lessa \\ Agência de Cursos — raymaraalves@yahoo.com.br
}

Introdução: São crescentes os indicadores de mortalidade por neoplasias no Brasil, atualmente perde apenas pelas doenças de causas cardiovasculares. Diante deste contexto, os pacientes que desenvolvem esse tipo de patologia sem possibilidade de cura, são direcionados aos cuidados paliativos - especialidade criada com a finalidade de fornecer meios para um novo conceito do cuidar, que busca não apenas a cura, mas uma assistência digna ao sujeito até o final de sua vida. Dentro dessa perspectiva, a Organização Mundial de Saúde (OMS) redefiniu cuidados paliativos como sendo o aprimoramento da qualidade de vida dos pacientes e de seus familiares que enfrentam problemas com doenças em fases terminais, tentando proporcionar 0 alívio do sofrimento, através da identificação precoce, avaliação correta e o tratamento da dor, e de outros problemas que venham a surgir no âmbito físico e psicossocial. Objetivo: Formular conhecimento científico para o desenvolvimento da prática humanizada dos cuidados paliativos frente às necessidades do paciente, da família e do profissional de saúde. Metodologia: Trata-se de uma revisão integrativa da literatura científica brasileira, na temática da prática dos cuidados paliativos e sua correlação com o cuidar da equipe de enfermagem utilizando as técnicas da humanização preconizadas pelo humanizaSUS. para isto, foi realizado um levantamento bibliográfico no qual foram revisados 05 (cinco) artigos, dos últimos 05 (cinco) anos, descritos na literatura científica brasileira, disponíveis na íntegra. para a busca destes artigos foram aplicados os descritores "cuidados paliativos"; "equipe de enfermagem"; "doente terminal", e "humanização", a fim de encontrar artigos na área da enfermagem, sendo posteriormente analisados e discutidos com foco no objetivo do estudo. Resultados: Sendo a ação desenvolvida por uma equipe multidisciplinar que trabalha diretamente com o paciente em fase terminal e cuja relação se estende ao contato contínuo com a família, os artigos apontaram que muitas vezes a maior dificuldade está no estabelecimento de uma relação entre o cuidar e sua aproximação com a perda do paciente. Os artigos também focam que muitos profissionais apresentaram pouco conhecimento no que diz respeito às estratégias de comunicação para o suporte emocional dos pacientes em cuidados paliativos e suas famílias. Conclusão: para a perspectiva de um cuidado humanizado o profissional de saúde precisa usar sua proatividade de forma reflexiva, para que a ação não se torne mecânica. Visto que estando inserido num momento de iminência do fim da vida do outro, podem surgir comportamentos que fogem à proposta de um cuidar humanizado. Entretanto, para que haja um feedback positivo na assistência à saúde, é preciso oferecer acompanhamento constante ao profissional paliativista, buscando interpretar sua ótica frente aos cuidados prestados ao paciente terminal. Desta forma é possível contribuir com a integralidade da assistência em saúde.

Silva, Raymara Alves da; Silva, Liniker Scolfild R. da; Fonsêca, Jéssica Ramalho da; Ramos, Ana Raquel Xavier; Correia, Nathália da Silva; Cordeiro, Eliana Lessa. Cuidados Paliativos Numa Visão Humanizada da Assistência de Enfermagem: Revisão Integrativa. In: Anais do Congresso Internacional de Humanidades \& Humanização em Saúde [= Blucher Medical Proceedings, num.2, vol.1]. São Paulo: Editora Blucher, 2014. ISSN 2357-7282 DOI 10.5151/medpro-cihhs-10713 